\title{
Téoros
}

Revue de recherche en tourisme

\section{Le marketing touristique : un sujet litigieux}

\section{Pierre Filiatrault}

Volume 3, numéro 1, mars 1984

Le marketing touristique : perspectives et limites

URI : https://id.erudit.org/iderudit/1080813ar

DOI : https://doi.org/10.7202/1080813ar

Aller au sommaire du numéro

Éditeur(s)

Université du Québec à Montréal

ISSN

0712-8657 (imprimé)

1923-2705 (numérique)

Découvrir la revue

Citer ce document

Filiatrault, P. (1984). Le marketing touristique : un sujet litigieux. Téoros, 3(1),

1-1. https://doi.org/10.7202/1080813ar d'utilisation que vous pouvez consulter en ligne.

https://apropos.erudit.org/fr/usagers/politique-dutilisation/ 


\section{Présentation}

\section{Le marketing touristique: un sujet litigieux}

Pourquoi choisir le marketing touristique comme theme d'un numéro de la revue Téoros? Le sujet ne manque sans doute pas d'intéret mais il est litigieux. I/ est hitigieux car il se trouve à la frontière de divers systèmes de valeurs. /l est aussi possiblement litigieux parce qu'on le connaît mal. Pour certains le marketing, c'est la publicité manipulative et agressive. Ceux-là niont sans doute jamais lu la pléthore de rapports de recherches scientifiques concernant la mesure de /impact de la publicité, rapports souvent contradictoires confirmant que le consommateur n'est pas un mollusque apprivoisé. Pour d'autres, le marketing fait concurrence aux milieux de /information et de la communication; pourtant la communication n'est qu'une variable a considerer et le vrai spécialiste du marketing sait qu'il doit avoir recours aux communicateurs pour présenter le message. II y a aussi le scepticisme et le mépris envers le marketing dans le secteur public qui masquent à peine la préoccupation de linclusion de cette nouvelle discipline dans ce milieu. On pourrait épiloguer longtemps, dans ce contexte politico-social, sur les raisons mettant en évidence le pour et le contre de f'utilisation du marketing en tourisme.

Nous ne nous proposons pas de trancher cette polémique dans le présent numéro de Téoros. Nous désirons plutót faire mieux connaître ce qu'est le marketing dans le secteur touristique. Le marketing n'est nila vente ni la publicité, c'est une activité humaine orientée vers la satisfaction des besoins et désirs des touristes grâce à des processus d'échange. La gestion du marketing consiste à préparer /'offre lle marketing $m i x$ / de lorganistion en fonction de la demande identifiée auprès des marchés-cibles en utilisant un produit, un prix, une distribution et une communication qui permettent d'informer, de motiver et de mieux servir ces marchés. La gestion de ce processus se fait par /analyse, la planification. /'exécution et le contröle de programmes mis en place pour créer, bâtir et maintenir des échanges et des relations réciproquement profitables avec les marchés-cibles dans le but d'atteindre les objectifs organisationnels. Les objectifs organisationne/s different évidemment si le marketing touristique est vu par un organisme public qui est orienté vers le développement touristique national, par exemple, ou s'ill est vu par une entreprise privée qui est au moins aussi préoccupée par sa survie que par son intégration à un plan de développement touristique régional.

Le vécu du marketing touristique variera donc selon les milieux. Nous présentons dans ce numéro des points de vue de divers intervenants de façon à mieux faire apprécier la complexité, le dynamisme et le potentiel du marketing dans le développement touristique.

Pierre Filiatrault et Jean-Charles Chebat se penchent sur I'utilisation du marketing dans le secteur du tourisme au Québec. Jacques Demers souligne la nécessité de développer un produit touristique valable avant de passer a la mise en marché alors que Luc Poirier explique la problématique du marketing au sein d'un ministère.

Jean-Alexandre Janowski explique la démarche suivie lors de la préparation d"une campagne intégrée de publicité touristique. Enfin. Pierre Desaulniers explique le vécu de /'elaboration d'un plan de marketing au sein d'une association d'organisations sans but lucratif. C'est là un vaste tour d'horizon qui saura sans doute vous intéresser. Bonne lecture.

\section{Pierre Filiatrault}

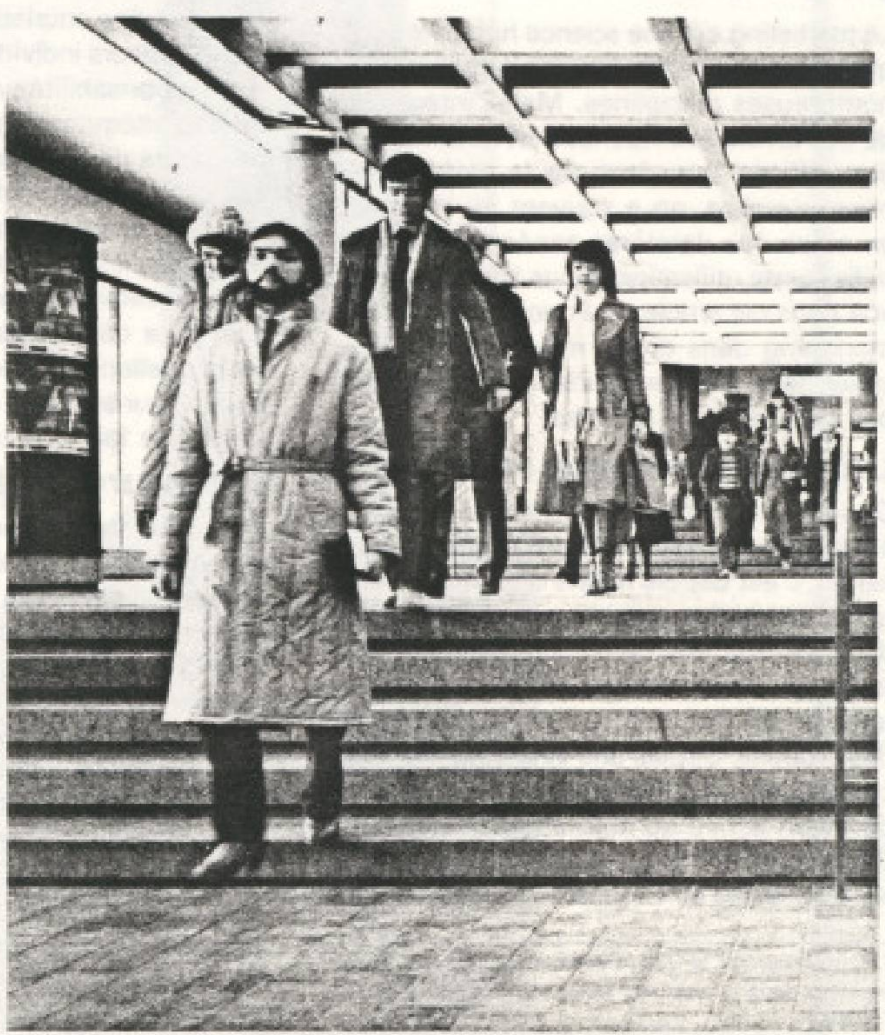

